\title{
Political Choices of the Left and the Right in Crises: An Experimental Investigation
}

\author{
Ishan Kashyap Hazarika ${ }^{1}$, Sourabh Rai ${ }^{2}$ and Anjali Verma ${ }^{3}$ \\ ${ }^{1,2 \& 3}$ Department of Economics, Hansraj College, University of Delhi, Delhi, India \\ E-mail: kpishanh@gmail.com
}

\begin{abstract}
While numerous studies have documented the difference in choice behaviour of the political Left and the Right, the effect of situations of a crisis on political choices have remained unexplored. This study aims to record and analyse such effects and investigate if any differences or similarities appear in the two groups. The study uses an experimental approach to the problem. Samples of leftists and rightists in India are randomly provided with forms to vote in either a normal situation or a hypothetical situation of crisis. The difference in voting behaviour in the two scenarios is noted. The difference in the change in the voting behaviour of the Left and the Right is also noted. It is found as expected that under normal circumstances, the Left and the Right have different voting patterns. But under crisis, when their leader performs badly, they shift to the opposite leader with almost the same probability. Also, not only the effect, but the voting patterns themselves become very similar during crises. The behaviour of the Left and Right sustain differences only in normal circumstances, but under crises, the differences may no longer remain extant.
\end{abstract}

Keywords: Political Choices, Crises, Experimental Investigation

\section{INTRODUCTION}

The sphere of politics is rife with differences in opinions and viewpoints about issues in different possible dimensions such as economic policies and social change to foreign affairs. Since the French Revolution, however, a onedimensional approach of classifying ideologies from the left to the right has gained acceptance (Heywood, 2017). The Left is largely identified with the political concern of equality, liberty, rights and internationalism while the Right is concerned with tradition, authority, reaction and nationalism. Several behavioural studies have since then documented numerous differences in the psycho-social characteristics of the leftists and the rightists. For example, right-leaning people are found to exhibit more egodefensive preferences, such as cleanliness and order, while left-leaning people exhibit care for open-mindedness and intellectual and imaginative modes of thinking (Feather, 1979). It is thus clear, that under normal circumstances, people on the Left exhibit different characteristics than those on the Right - they form different political parties and support different causes and movements. In most discussions, for instance, Anarchism, Communism, Socialism, Racial Equality etc. are considered left-wing while Conservatism, Traditionalism, Fascism, Reaction etc. are considered right-wing. There also exist movements, however, that are difficult to classify, such as Regionalism, Feminism and Environmentalism (Dobson, 1995). The formation of these preferences is a more nuanced topic. In many rational-choice analyses of this topic, just like consumer preferences, voter preferences are also considered exogenously given. For example, in the classic book by Downs in 1957, "An Economic Theory of Democracy", when the 'Median Voter Theorem' is discussed, the distribution of voters on the Left-Right spectrum is considered to be given exogenously. Downs only assumes the preferences to be single-peaked for convenience (Downs, 1957).

An empirical finding regarding what can partially lead to political-leaning, relevant for our study, considers riskaversion. It has been found that in business ventures, conservatives are more willing to take a risk (Choma et al., 2014) Societal risk-aversion is also considered a vital indicator of inequality-aversion, a left-wing characteristic (Carlson et al., 2005). In general, left-wing voters are found to be both more risk-averse and inequality-averse. Another interesting finding is that while conservatives consider 'personal hazards to be riskier, liberals feel 'social hazards' are riskier (Choma et al., 2013). Under conditions of crisis, such as the COVID19 pandemic, an informal view might suggest that higher levels of risk may prompt people to behave in a more left-wing manner, or perhaps the effects will be different altogether.

Another perspective to look at this problem could be to consider the worship of leaders and the feeling of disgust. The COVID19 pandemic might irk right-leaning individuals more as they care more about cleanliness, as discussed above. In fact, it has been found that the probability of authoritarian regimes arising is significantly higher in areas with a higher prevalence of infectious disease (Murray et al., 2013). The ego-centric nature of right-leaning people may also play a role in the way the performance of leaders is seen in the crisis.

Thus, competing forces are at play on an informal level, making how the left and the right will behave in such situations of crisis very unclear. We were not able to find any study to mention regarding the choice-behaviour of leftists and rightists in situations of crisis as opposed to normal circumstances. This precisely is the gap in research 
that this study seeks to fill. Elaborating, the following are the concerns for this study.

1. To identify the Left and the Right in the sample and to verify that they vote differently in normal circumstances.

2. To find whether the difference persists in the face of a crisis.

3. To see whether the effect of the crisis on the choicebehaviour is different for Leftists and Rightists.

\section{EXPERIMENTAL DESIGN AND CHARACTERISTICS OF THE SAMPLE}

To search for answers to the questions posed in this study, we adopt an experimental approach. In particular, we design a Randomised-Control Experiment framework, where the intervention is the introduction of a situation of crisis.

We layout the process as follows.

1. We consider a sample of people whose political leanings are unknown and administer a psychometric test to identify their leanings. We use the 12-item Social and Economic Conservatism Scale (SECS) developed in Everett (2013) to obtain the 'conservatism' scores from 0 to 10 , a higher score indicating more affinity to conservatism. The test asks respondents to inform how "warm" they feel when reading a particular term such as "abortion”, "welfare”, "traditional values", "business” etc., totalling 12 items. This utilises the 'psychological-thermometer scale' apparatus to avoid specific miscommunication by avoiding sentences and using terms instead.

2. After attaining the SECS scores, we evaluate the median score. We put everyone scoring greater than or equal to the median in the "Right-Wing" group while the rest are put in the "Left-Wing” Group.

3. Within the right-wing group, randomly half of the people are given the "Normal Situation Form”, where they are asked to vote for one of two candidates for the post of the prime minister of a fictional country. The description does not provide any indication of crisis. One of the candidates is shown to support left-wing values (based on the literature discussed in the previous section) and the other is shown to support right-wing values.

4. The other half of the right-wing group is given the "Crisis Situation Form for Rightists", where they too are asked to vote for one of two fictional candidates. This time, however, the description of the election in the form clearly states that the election is taking place "during the COVID19 pandemic" while assuring that the "election commission has assured full safety". In addition to that, additional information is introduced. The right-wing candidate, it is stated, had performed badly during the H1N1 Influenza outbreak of 2009 when he/she (the form used the term 'Candidate 1 ' to hide the gender) was the chief minister of his state, while the left-wing candidate had performed very well then, in his/her (the form used the term 'Candidate 2') respective state. This is done to create a dilemma for the respondents.

5. Similarly, randomly half of the people in the left-wing group are given the "Normal Situation Form" which is completely identical to the one for the right-wing group.

6. The other half of the left-wing group is given the "Crisis Situation Form for Leftists", which is completely identical to the "Crisis Situation Form for Rightists" except that the performance records of the candidates are reversed. That is, in this form, instead of the right-wing candidate, the left-wing candidate is said to have performed badly in the H1N1 Influenza outbreak of 2009 while the Right Wing candidate had performed well. This again is done to create a dilemma for the left-wing respondents. The aim is to see whether the leftists and rightists would react differently to this dilemma.

Do note that none of the respondents was aware that other respondents were given different forms. The forms handed out did not spell out "Crisis Situation Form for Leftists" etc. but a generic "Research Survey" was used as the heading. Because the information about the past performance of the candidates was swapped for leftists and rightists, the dependent variable of interest is not whether the vote is given to candidate 1 or candidate 2, but whether there has been cross-voting or not. Accordingly, we define a Bernoulli variable $Y$ which assumes the value 1 when a person votes for the candidate of his/her own political leaning, that is, a left-leaning person votes for the left-wing candidate or a right-leaning person votes for the right-wing candidate. The value is 0 otherwise. We expect the average value of $Y$ to be low in the crisis situation for both leftists and rightists. The question of interest is whether the drop in the mean of $Y$ is different for leftists and rightists. The total sample size is 119 , out of which, 58 were categorised as right-wing (those who scored higher than the median) and the rest were categorised as left-wing.

We shall proceed to conduct two different statistical analyses on the data. Firstly, we shall conduct simple ChiSquare Tests of Independence on the 'normal situation respondents and the 'crisis situation respondents separately. We see whether the distribution of $Y$ is dependent on the political leaning of the respondent in the normal situation and whether the difference remains extant in the situation of crisis.

Secondly, we fit a Binary-Logistic Regression model in the data with an interaction term, combining the Difference-inDifference approach with the Binary-Logistic Regression. Specifically, let $X_{1}$ indicate the political inclination of the respondent ( 0 for Left and 1 for Right) and let $X_{2}$ indicate the situation under which the respondent voted ( 0 for normal and 1 for crisis). Then a simple Difference-inDifference model would be of the following form

$$
P\left(Y=1 \mid X_{1}, X_{2}\right)=\beta_{0}+\beta_{1} X_{1}+\beta_{2} X_{2}+\beta_{3} X_{1} X_{2}
$$


Here, the coefficient $\beta_{3}$ would indicate the difference in the effect of the crisis on leftists and rightists. But because the LHS is a probability, we augment it with the Binary-

Logistic model to run the following instead

$$
P\left(Y=1 \mid X_{1} X_{2}\right)=f\left(\beta_{0}+\beta_{1} X_{1}+\beta_{2} X_{2}+\beta_{3} X_{1} X_{2}\right)
$$

Here, $f$ is the logistic function.

The following are our hypotheses

$$
\begin{aligned}
& H_{0}: \beta_{3}=0 \\
& H_{1}: \beta_{3} \neq 0
\end{aligned}
$$

\section{RESULTS AND DISCUSSION}

\section{A. Chi-Square Test of Independence}

We tabulate the number of respondents with $Y=1$ and $Y=0$ according to their political-leaning below, separately for the normal situation and the situation of crisis.
TABLE I CROSS-TABULATION IN THE NORMAL SITUATION

\begin{tabular}{|c|c|c|c|c|}
\hline \multirow{4}{*}{ Ideology } & \multicolumn{3}{|c|}{ Y- Value } & Total \\
\cline { 2 - 5 } & & $\mathrm{Y}=0$ & $\mathrm{Y}=1$ & \\
\cline { 2 - 5 } & Left & 10 & 19 & 29 \\
\cline { 2 - 5 } & Right & 16 & 10 & 26 \\
\hline Total & & 26 & 29 & 55 \\
\hline
\end{tabular}

TABLE II CROSS-TABULATION IN THE SITUATION OF CRISIS

\begin{tabular}{|c|c|c|c|c|}
\hline \multirow{4}{*}{ Ideology } & \multicolumn{3}{|c|}{ Y- Value } & Total \\
\cline { 2 - 5 } & & $\mathrm{Y}=0$ & $\mathrm{Y}=1$ & \\
\cline { 2 - 5 } & Left & 18 & 14 & 32 \\
\cline { 2 - 5 } & Right & 22 & 10 & 32 \\
\hline Total & & 40 & 24 & 64 \\
\hline
\end{tabular}

We now proceed to run the Chi-Square Test of Independence, with a level of significance of $10 \%$ on the two tables separately. For the normal situation, we find the following results.

TABLE III RESULTS OF THE CHI-SQUARE TEST IN THE NORMAL SITUATION

\begin{tabular}{|l|c|c|c|c|c|}
\hline & Value & $\begin{array}{c}\text { Degrees of } \\
\text { Freedom }\end{array}$ & $\begin{array}{c}\text { Asymptotic } \\
\text { Significance(2-sided) }\end{array}$ & $\begin{array}{c}\text { Exact Significance } \\
\text { (2-sided) }\end{array}$ & $\begin{array}{c}\text { Exact Significance } \\
\text { (1-sided) }\end{array}$ \\
\hline Pearson Chi-Square & 4.026 & 1 & 0.045 & & \\
\hline Continuity Correction & 3.014 & 1 & 0.083 & & \\
\hline Likelihood Ratio & & 1 & 0.044 & & 0.060 \\
\hline Fisher's Exact Test & & & & & \\
\hline Linear-by-Linear Association & & 1 & 0.047 & & \\
\hline Number of Valid Cases & 55 & & & & \\
\hline
\end{tabular}

The Pearson Chi-Square Test (2-sided), yields a p-value of 0.045 . This is significant at the $10 \%$ level of significance. Therefore we conclude that the level of cross-voting is statistically different in Leftists than in Rightists, under normal circumstances.

For the situation of crisis, the following are the results.

TABLE IV RESULTS OF THE CHI-SQUARE TEST IN THE SITUATION OF CRISIS

\begin{tabular}{|l|c|c|c|c|c|}
\hline & Value & $\begin{array}{c}\text { Degrees of } \\
\text { Freedom }\end{array}$ & $\begin{array}{c}\text { Asymptotic } \\
\text { Significance (2-sided) }\end{array}$ & $\begin{array}{c}\text { Exact Significance } \\
\text { (2-sided) }\end{array}$ & $\begin{array}{c}\text { Exact Significance } \\
\text { (1-sided) }\end{array}$ \\
\hline Pearson Chi-Square & 1.067 & 1 & 0.302 & & \\
\hline Continuity Correction & 0.600 & 1 & 0.439 & & \\
\hline Likelihood Ratio & & 1 & 0.301 & & 0.439 \\
\hline Fisher's Exact Test & & & & & \\
\hline Linear-by-Linear Association & & 1 & 0.306 & & \\
\hline Number of Valid Cases & 64 & & & & \\
\hline
\end{tabular}

The Pearson Chi-Square Test (2-sided), yields a p-value of 0.302 in this case. This is not significant at the $10 \%$ level of significance.

Therefore, we conclude that the cross-voting behaviours of Leftists and Rightists are not statistically significantly different in the situation of crisis.

\section{B. Binary-Logistic Regression}

We now proceed to implement a Binary-Logistic Regression on the data to see whether the effect of the crisis is different on Leftists and Rightists or the same. Checking the necessary assumptions, we find that they are fulfilled to a satisfactory degree. The following is the correlation matrix for the independent variables. 
TABLE V CORRELATION MATRIX OF INDEPENDENT VARIABLES

\begin{tabular}{|l|c|c|c|}
\hline & Ideology & Situation & Interaction \\
\hline Ideology & 1 & & \\
\hline Situation & 0.027 & 1 & \\
\hline Interaction & 0.621 & 0.562 & 1 \\
\hline
\end{tabular}

The correlation coefficients are below the threshold of 0.8 , which is satisfactory for us to rule out multicollinearity. The sample size is 119, which is well above the required minimum sample size of 68 for 3 independent variables and an unconditional probability of 0.445 for the least frequent outcome.
Thus, we are in a position to fit the Binary-Logistic Regression model and interpret it. We present the results of the baseline case first.

TABLE VI THE CLASSIFICATION TABLE FOR THE BASELINE MODEL

\begin{tabular}{|c|c|c|c|c|c|}
\hline \multirow{6}{*}{ Step 0} & & & \multicolumn{2}{|c|}{ Predicted } & \\
\hline & & & \multicolumn{2}{|c|}{ Loyalty } & \\
\hline & Observed & & 0 & 1 & \\
\hline & Jonlty & 0 & 66 & 0 & 100 \\
\hline & & 1 & 53 & 0 & 0 \\
\hline & Overall Percentage & & & & 55.5 \\
\hline
\end{tabular}

TABLE VII TESTS ON THE VARIABLES IN THE BASELINE MODEL

\begin{tabular}{|c|c|c|c|c|c|c|}
\hline & B & Standard Error & Wald Statistic & Degrees of Freedom & Significance & $\operatorname{exp(B)}$ \\
\hline Constant & -0.219 & 0.184 & 1.414 & 1 & 0.234 & 0.803 \\
\hline
\end{tabular}

The baseline model was able to predict $55.5 \%$ of the

We now present the results of the full model. outcomes. The p-value for the constant is 0.234 , which exceeds the threshold of $10 \%$.

TABLE VIII RESULTS OF THE BINARY-LOGISTIC REGRESSION MODEL

\begin{tabular}{|c|l|c|c|c|c|c|c|}
\hline & & B & Standard Error & Wald Statistic & Degrees of Freedom & Significance & exp(B) \\
\cline { 2 - 8 } & Ideology & -1.112 & 0.561 & 3.923 & 1 & 0.048 & 0.329 \\
\cline { 2 - 8 } & Situation & -0.893 & 0.529 & 2.853 & 1 & 0.091 & 0.409 \\
\cline { 2 - 8 } & Interaction & 0.575 & 0.767 & 0.562 & 1 & 0.453 & 1.777 \\
\cline { 2 - 9 } & Constant & 0.642 & 0.391 & 2.699 & 1 & 0.100 & 1.900 \\
\hline
\end{tabular}

TABLE IX THE CLASSIFICATION TABLE FOR THE FULL BINARYLOGISTIC REGRESSION MODEL

\begin{tabular}{|c|c|c|c|c|c|}
\hline \multirow{6}{*}{ Step 0} & & & \multicolumn{2}{|c|}{ Predicted } & \\
\hline & & & \multicolumn{2}{|c|}{ Loyalty } & \\
\hline & Observed & & 0 & 1 & \\
\hline & \multirow{2}{*}{ Loyalty } & 0 & 56 & 10 & 84.8 \\
\hline & & 1 & 34 & 19 & 35.8 \\
\hline & Overall Percentage & & & & 63.0 \\
\hline
\end{tabular}

TABLE X MODEL SUMMARY

\begin{tabular}{|c|c|c|c|}
\hline Step & $\begin{array}{c}-2 \text { Log } \\
\text { Likelihood }\end{array}$ & $\begin{array}{c}\text { Cox and Snell } \\
\text { R Square }\end{array}$ & $\begin{array}{c}\text { Negelkerke } \\
\text { R Square }\end{array}$ \\
\hline 1 & 155.619 & 0.064 & 0.086 \\
\hline
\end{tabular}

The full model is able to correctly predict the outcome $63 \%$ of the time. The Cox and Snell R Square is $6.4 \%$ and the Negelkerke R Square is $8.6 \%$. This however cannot be interpreted as the CLRM $\mathrm{R}$ Square and we need other values to compare it to. We will not delve into that, however, as we are more concerned with the values of the B-coefficients.

Both 'ideology' and 'situation' have statistically significant non-zero coefficients, with 0.048 and 0.091 as the respective p-values, which are statistically significant at the
$10 \%$ level of significance. Thus, the probability of crossvoting is affected by both ideology and the situation. However, the effect of a change in situation, that is introduction of a crisis as an intervention, does not affect the Left and the Right differently, as the coefficient of the 'interaction' term has a p-value of 0.453 , which is not statistically significant at $10 \%$ level of significance.

\section{CONCLUSION}

We have observed through the experiment conducted, that choice-behaviour can change when crisis knocks. Under normal circumstances, the Left and the Right have different cross-voting behaviours. They mostly vote along their ideological lines. But when during a crisis, their leader performs badly, the difference between the Left and the Right disappears, as revealed through the Chi-Square Tests. The amount of cross-voting is similar for both the Left and the Right under a situation of crisis. The results from the Binary-Logistic Regression model also show that there is an effect of the introduction of a crisis on the voting behaviours of both the Left and the Right, at least when their leader performs badly, but the intensity of the effect is not significantly different for the Left and the Right. These findings shed light on how people of different political inclinations are affected during a crisis regarding their choice behaviour. The results indicate that it would be 
equally difficult for the leftist and the rightist leaders when they are not able to perform well under situations of crisis. These are interesting results and help in gaining a more nuanced understanding of political behaviour. The experiment can be repeated in future studies with a more internationally representative sample or perhaps with specialised samples for different regions to gain a fuller picture. Like many psycho-social findings, ours may too be contingent on many social factors, though full care was taken to include respondents from different parts of India. The findings are, we assert, at least of interest in India and may be replicated in the future for other regions and circumstances or age groups.

\section{REFERENCES}

[1] Heywood, A. (2017). Political Ideologies: An Introduction. (6 ${ }^{\text {th }}$ Ed.) Basingstoke: McMillan International Higher Education. 14-17.

[2] Feather, N. T. (1979). Value Correlates of Conservatism. Journal of Personality and Social Psychology, 37(9), 1617-1630. DOI: 10.1037/0022-3514.37.9.1617
[3] Dobson, A. (1995). Green Political Thought. (3 ${ }^{\text {rd }}$ Ed.). 27-28.

[4] Downs, A. (1957). An Economic Theory of Democracy. New York: Harper and Brothers.

[5] Choma, B., Hanoch, Y., Hodson, G. and Gummerum, M. (2014). Risk Propensity among Liberals and Conservatives: The Effect of Risk Perception, Expected Benefits and Risk Domain. Social Psychological and Personality Science, 5, 713-721. DOI: 10.1177/1948550613519682.

[6] Carlson, F., Daruwala, D. and Johanson, S. O. (2005). Are People Inequality-Averse or Just Risk Averse? Economica. 72(287):375-396.

[7] Choma, B. L., Hanoch, Y., Gummerun, M. and Hodson, G. (2013). Risk Propensity among Liberals and Conservatives: The Effect of Risk Perception, Expected Benefits and Risk Domain. Personality and Individual Differences, 54(1): 29-34.

[8] Murray, D. R., Schaller, M. and Suedfeld, P. (2013). Pathogens and Politics: Further Evidence that Parasite Prevalence Predicts Authoritarianism. PLOS One, 8(5) e62275. DOI: 10.1371/journal.pone.0062275.

[9] Everett, J. A. C. (2013). The 12-Item Social and Economic Conservatism Scale (SECS). PLOS One, 8(12): e82131. DOI: 10.1371/journal.pone.0082131. 